\title{
Inventory Simulation under Uncertainty Demand with Conditional Distribution
}

\author{
${ }^{1}$ Meriandela Angkat, ${ }^{2}$ Wita Handayani, ${ }^{3}$ Rinnasa Perangin Angin \\ ${ }^{1}$ SMAN 2 Kejuruan Muda \\ ${ }^{2}$ SMK Negeri 2 Binjai \\ ${ }^{1,2,3}$ Department of Mathematics, University of North Sumatera, Indonesia
}

\begin{abstract}
The sales forecast is a prerequisite for the inventory decisions in the practical life. The right selection of the forecasting model to improve the inventory management can increase the customer service level and determine a better performance for the supply chain. The forecast performance should not only be evaluated by its standard error, but also its impact in the organization performance measures. The sales forecast should not be considered an individual function, but as an important part of supply chain management. By using simulation, managers are able to create a model of their supply chain systems and test various levels of input that can emulate real-life inconsistencies. We assume that we can model the supply chain as a network that each stage in the supply chain operates with a periodic review base-stock policy, that demand is bounded and that there is guaranteed service time between every stage and its customers. This study uses the analytic solver program in excel that does the randomization process on the variable demand.
\end{abstract}

Keywords: Uncertainty demand, Supply Chain, Inventory

\section{Introduction}

Manufacturing firms are introducing new products at a higher frequency with increasingly shorter life cycles. For each new product, a firm must determine its supply chain and the associated operating policies to match supply to the demand to achieve the most revenue with the least cost. A major complication is that the demand process evolves over the product life cycle and is never stationary.

The product life cycle of a new product typically consists of four phases: (i) a product-launch phase in which the product is introduced to the market; (ii) a demand-ramp phase over which the demand rate grows rapidly; (iii) a peak-demand phase during which the product sells at its maximum rate; and (iv) an end-of-life phase during which the product demand declines as it is removed from the market.

The demand rate is never stationary because the product moves from one life-cycle phase to another. This research examines the problem of locating safety stocks in a supply chain in a way that accounts for uncertain, uncertainty demand processes. Given the inherent complexity of modeling uncertainty demand processes, we seek a pragmatic approach that requires approximations and compromises to get results that might apply in practice. We use the modeling framework from Graves and Willems (2000) (referenced as G-W) and introduce a uncertainty demand model. We show that the G-W safety stock placement optimization applies to this case of uncertainty demand.

In the remainder of this section, we briefly discuss related literature. In $\S 2$, we present the key assumptions for modeling a supply chain and its uncertainty demand. In $\S 3$, we extend the G-W model to accommodate uncertainty demand. In $\S 4$, we examine a simple example to explore the near optimality of a constant service time (CST) policy.

\section{Related Literature}

Relative to the stationary-demand inventory literature, there is much less work for uncertainty demand. We characterize this work by how the uncertainty demand is specified and whether the work focuses on optimization versus performance evaluation. Morton and Pentico (1995) and Bollapragada and Morton (1999) focus on setting inventory policies for a single stage facing a general uncertainty demand process with proportional holding and backorder costs. When the order cost is zero, a time-varying base-stock policy is optimal; for a nonzero order cost, a time-varying policy is optimal. This research develops computationally efficient upper and lower bounds on these optimal policies. For short life cycle products, the challenge of accurately forecasting demand can be as important as determining inventory policies. Kurawarwala and Matsuo (1996) develop an integrated framework for forecasting and inventory management of short lifecycle products. Their approach estimates the parameters for a seasonal trend growth model and uses this as an input to a finite-horizon stochastic inventory model with time-dependent demands.

Uncertainty demand has also been modeled as a Markovmodulated Poisson demand process. One example is Chen and Song (2001), who show the optimality of echelon basestock policies with state dependent order-up-to levels for serial networks. A second example is Abhyankar and Graves (2001) who determine the optimal position of an inventory hedge in a two-stage serial supply chain that faces Markov modulated demand with two states. Within the bullwhip literature, several papers develop models for uncertainty demand.

Papers generally assume that each stage follows an adaptive base-stock policy and then analyze the effect that different forecasting techniques and assumed demand distributions have on the inventory requirements at each stage. For instance, Lee et al. (1997) demonstrate that the adjustment of order-up-to levels at the retailer amplifies the variance of the 


\section{International Journal of Science and Research (IJSR) \\ ISSN (Online): 2319-7064}

Index Copernicus Value (2013): 6.14 | Impact Factor (2015): 6.391

order signal the retailer provides for the manufacturer. Two other examples are Graves (1999) and Chen et al. (2000).

Finally, there is a growing body of work on designing supply chains to handle uncertainty demand. Beyer and Ward (2000) use simulation to accurately model the inventory requirements in a two-echelon supply chain that utilizes two modes of distribution and is subject to uncertainty demand. Johnson and Anderson (2000) investigate the benefits of postponement in supply chains that introduce multiple products with short product life cycles. Ettl et al. (2000) minimize the total inventory in a multistage inventory system, where the key challenge is to approximate the replenishment lead times within the supply chain. To model uncertainty demand, they break the horizon into a set of stationary phases and adopt a rolling-horizon approach where the optimization is performed for each demand phase.

\section{Supply Chain Model}

In this section, we present the multistage model of a supply chain and the optimization problem for determining safety stocks. Graves and Willem (2008) show the model (D is maximum demand in interval time $(\mathrm{s}, \mathrm{t})$ :

$$
g_{j}(s, t)=D_{j}(s, t)-\int_{\tau=s}^{t} \mu_{j}(\tau) d \tau .
$$

\section{Inventory Model}

The single-stage inventory model serves as the building block for modeling a multistage supply chain. We adapt the standard model of Kimball (1988) (see also Simpson 1958) to the case of uncertainty demand.

We define the inbound service time SI, as the time for stage $\mathrm{j}$ to get supplies from its immediate suppliers. In each period $t$, stage $\mathrm{j}$ places an order equal to $\phi_{\mathrm{ij}} \mathrm{d}_{\mathrm{j}}(\mathrm{t})$ on each upstream stage $\mathrm{i}$ for which $\phi_{\mathrm{ij}}>0$. The time for all orders to be delivered to stage $\mathrm{j}$ dictates when stage $\mathrm{j}$ can commence production to replenish its demand. This inbound service time is constrained by the maximum outbound service time from the upstream suppliers, i.e, $\mathrm{SI}_{\mathrm{ij}} \geq \max _{(\mathrm{i}, \mathrm{j}) \in \mathrm{A}}\left(\mathrm{S}_{\mathrm{i})}\right.$.

We assume we are given base stocks $\mathrm{B}_{\mathrm{j}}(\mathrm{t})$ for each period $\mathrm{t}=1,2, \ldots, \mathrm{H}$. For the stated assumptions, we can express the inventory at stage $\mathrm{j}$ at the end of period $\mathrm{t}$ as

$$
I_{j}(t)=B_{j}(t)-d_{j}\left(t-S I_{j}-T_{j}, t-S_{j}\right)(2)
$$

where $d_{j}(s, t)=0$ for $s \leq t \leq 0$ and $d_{j}(s, t)=d_{j}(0, t)$ for $s$ $<0<t$.

We defined the net replenishment time for stage $\mathrm{j}$ to be its replenishment time, net the stage's promised outbound service time, i.e., $\mathrm{SI}_{\mathrm{j}}+\mathrm{T}_{\mathrm{j}}-\mathrm{S}_{\mathrm{j}}$. This net replenishment time determines the safety stock at stage $\mathrm{j}$. We always set the outbound service times so that the net replenishment time is nonnegative.

The explanation for Equation (2) follows that for the case stationary or certainty demand. There are three transactions in period $\mathrm{t}$ : stage $\mathrm{j}$ completes the replenishment of its demand from period $t-\mathrm{SI}_{\mathrm{j}}-\mathrm{T}_{\mathrm{j}}$; stage $\mathrm{j}$ fills its demand from period $\mathrm{t}-\mathrm{S}_{\mathrm{j}}$; and stage $\mathrm{j}$ receives an additional replenishment equal to $\Delta \mathrm{B}_{\mathrm{j}}(\mathrm{t})=\mathrm{B}_{\mathrm{j}}(\mathrm{t})-\mathrm{B}_{\mathrm{j}}(\mathrm{t}-1)$ so as to have the prescribed base-stock level. Hence, we can write an inventory balance equation:

$$
\begin{aligned}
I_{j}(t)=I_{j}(t-1) & +d_{j}\left(t-S I_{j}-T_{j}\right)-d_{j}\left(t-\mathrm{S}_{j}\right) \\
& +\Delta B_{j}(t) \ldots \ldots \ldots(3)
\end{aligned}
$$

We obtain (2) by applying (3) recursively and using the boundary condition $\mathrm{I}_{\mathrm{j}}(0)=\mathrm{B}_{\mathrm{j}}(0)$.

To derive Equation (2), we implicitly assume that we can always make the necessary adjustment $\Delta \mathrm{B}_{\mathrm{j}}(\mathrm{t})$ to the basestock level. This need not be the case when the base-stock level decreases and $\Delta \mathrm{B}_{\mathrm{j}}(\mathrm{t})<0$; in effect, we need to assume that $\mathrm{d}_{\mathrm{j}}\left(\mathrm{t}-\mathrm{SI}_{\mathrm{j}}-\mathrm{T}\right)+\Delta \mathrm{B}_{\mathrm{j}}(\mathrm{t}) \geq 0$ so that the replenishment in period $\mathrm{t}$ is nonnegative. We expect this will typically be the case, and we assume this to be true so as not to overly complicate the presentation. (We note that when $\mathrm{d}_{\mathrm{j}}\left(\mathrm{t}-\mathrm{SI}_{\mathrm{j}}-\mathrm{T}\right)+\Delta \mathrm{B}_{\mathrm{j}}(\mathrm{t})<0$, then Equation (2) provides a lower bound on the actual inventory level.)

\section{Determination of Base Stock}

For stage $\mathrm{j}$ to provide $100 \%$ service to its customers, we require that $\mathrm{I}_{\mathrm{j}}(\mathrm{t}) \geq 0$; we see from Equation (2) that this requirement equates to

Because demand is bounded, we satisfy the above requirement with the least inventory by setting the base

stock as

$$
\begin{gathered}
B_{j}(t) \geq d_{j}\left(t-S I_{j}-T_{j}, t-S_{j}\right) \\
B_{j}(t)=D_{j}\left(t-S I_{j}-T_{j}, t-S_{j}\right) \ldots \ldots
\end{gathered}
$$

Thus, the base-stock level in period $t$ is the maximum possible demand over a time interval $\left(\mathrm{t}-\mathrm{SI}_{\mathrm{j}}-\mathrm{T}_{\mathrm{j}-}, \mathrm{t}-\mathrm{S}_{\mathrm{j}}\right)$ for which stage $\mathrm{j}$ filled its demand, but has yet to receive replenishments.

\section{Safety Stock Model}

We use Equations (2) and (4) to find the expected inventory level $\mathrm{E}\left[\mathrm{I}_{\mathrm{j}}(\mathrm{t})\right]$ :

$$
\begin{aligned}
& \quad E\left[I_{j}(t)\right]=D_{j}\left(t-S I_{j}-T_{j}, t-S_{j}\right) \int_{\tau=s}^{t} \mu_{j}(\tau) d \tau \\
& =g_{j}\left(t-S I_{j}-T_{j}, t-S_{j}\right) .(5)
\end{aligned}
$$

The expected inventory represents the safety stock held at stage $\mathrm{j}$ and depends on the net replenishment time and the demand bound. We observe that stage $\mathrm{j}$ holds no safety stock whenever the net replenishment time is zero, i.e., $\mathrm{SI}_{\mathrm{j}}+\mathrm{T}_{\mathrm{j}}-\mathrm{S}_{\mathrm{j}}=0$.

The supply chain will also have a work-in-process or pipeline inventory. This inventory corresponds to the replenishment of customer demand plus the planned adjustments to the basestock levels. If we fix the base-stock levels for the start and end of the planning horizon, then we can show that the work 


\section{International Journal of Science and Research (IJSR) \\ ISSN (Online): 2319-7064}

Index Copernicus Value (2013): 6.14 | Impact Factor (2015): 6.391

in process does not depend on the choice of service times, but only on the average demand rates and the lead times at each stage. Hence, in posing an optimization problem, we ignore work-in-process and only model safety stock.

\section{Multistage Model}

To model the multistage system, we use Equation (5) for each stage where inbound service time is a function of the outbound service times for the upstream stages. We then formulate an optimization problem to find the optimal service times for the planning horizon:

$$
\begin{gathered}
\operatorname{P~Min~} \sum_{t=1}^{H} \sum_{j=1}^{N} h_{j} E\left[\left(I_{t}\right)\right] \\
=\sum_{t=1}^{H} \sum_{j=1}^{N} h_{j} g_{j}\left(t-S_{j}-T_{j}, t-S_{j}\right) \\
\text { Subject to } \\
S_{j}-S_{j} \leq T_{j} \text { for } j=1, \ldots, N \\
S_{j}-S_{j} \geq 0 \forall(i, j) \in A \\
S_{j}=0 \forall \text { demand nodes } j \\
S_{j}, S_{j} \geq 0 \text { integer for } j=1, \ldots, N
\end{gathered}
$$

where hj denotes the holding cost per unit per time period for inventory at stage $\mathrm{j}$. The objective of problem $\mathrm{P}$ is to minimize the safety stock holding cost over the planning horizon. The constraints assure that the net replenishment times are nonnegative, that each stage's inbound service time is no less than the maximum outbound service time quoted to the stage, and that the end-item stages satisfy their service guarantee. 3

We define the planning model to end in period $\mathrm{H}$ and do not explicitly include any costs beyond this horizon. For instance, if $\mathrm{H}$ represents the end of the life cycle for a product, there would be disposal costs for the supply chain inventory left over at the end of the horizon. We could include a disposal cost by restating $\mathrm{P}$ with time-dependent holding costs.

To solve $\mathrm{P}$, we first observe that we can rewrite the objective function as

$$
\begin{gathered}
\sum_{\mathrm{t}=1}^{\mathrm{H}} \sum_{\mathrm{j}=1}^{\mathrm{N}} \mathrm{h}_{\mathrm{j}} \mathrm{g}_{\mathrm{j}}\left(\mathrm{t}-\mathrm{SI}_{\mathrm{j}}-\mathrm{T}_{\mathrm{j}}, \mathrm{t}-\mathrm{S}_{\mathrm{j}}\right)=\mathrm{H} \times \sum_{\mathrm{j}=1}^{\mathrm{N}} \mathrm{h}_{\mathrm{j}} \mathrm{G}_{\mathrm{j}}\left(\mathrm{S}_{\mathrm{j}}, \mathrm{SI}_{\mathrm{j}}\right) \\
\text { Where } \mathrm{G}_{\mathrm{j}}\left(\mathrm{S}_{\mathrm{j}}, \mathrm{SI}_{\mathrm{j}}\right)=\mathrm{H}^{-1} \times \sum_{\mathrm{t}=1}^{\mathrm{N}} \mathrm{g}_{\mathrm{j}}\left(\mathrm{t}-\mathrm{SI}_{\mathrm{j}}-\mathrm{T}_{\mathrm{j}}, \mathrm{t}-\mathrm{S}_{\mathrm{j}}\right)
\end{gathered}
$$

is the average safety stock at node $\mathrm{j}$ as a function of its inbound and outbound service times. Thus, $\mathrm{P}$ is equivalent to the safety stock optimization problem for stationary demand in G-W, but with its objective function expressed in terms of the average safety stock $\mathrm{G}_{\mathrm{j}}\left(\mathrm{SI}_{\mathrm{j}}, \mathrm{S}_{\mathrm{j}}\right)$ over the planning horizon $\mathrm{H}$.

\section{Furthermore,}

$\mathrm{G}_{\mathrm{j}}\left(\mathrm{SI}_{\mathrm{j}}, \mathrm{S}_{\mathrm{j}}\right)$ is a concave function, given the assumption that the net demand bound $\mathrm{g}_{\mathrm{j}}(\mathrm{s}, \mathrm{t})$ is a concave function. As a consequence, we can solve $\mathrm{P}$ with the existing algorithms for stationary demand. G-W presents a dynamic programming algorithm for solving $\mathrm{P}$ for supply chains modeled as spanning trees; Humair and Willems (2006), Magnanti et al. (2006), and Lesnaia (2004) have each developed and tested algorithms for general acyclic networks.

\section{Numerical Results}

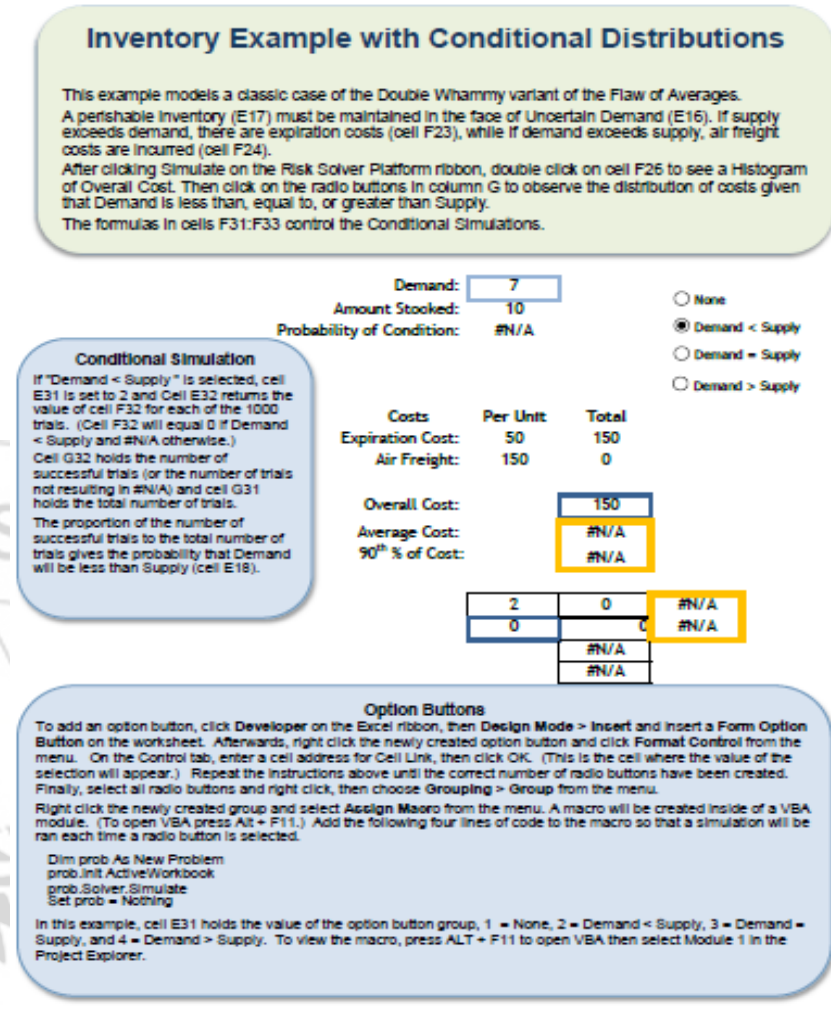

\section{Conditional Simulation}

If "Demand < Supply " is selected, cell E31 is set to 2 and Cell E32 returns the value of cell F32 for each of the 1000 trials. (Cell F32 will equal 0 if Demand < Supply and \#N/A otherwise.)

Cell G32 holds the number of successful trials (or the number of trials not resulting in \#N/A) and cell G31 holds the total number of trials.

The proportion of the number of successful trials to the total number of trials gives the probability that Demand will be less than Supply (cell E18).

\section{Conclusion}

In this study, it has been reviewed a model of placement safety stock in a supply chain (inventory) with conditional distributions. We can change the distribution of costs given that Demand is less than, equal to, or greater than Supply and then we observe these.

\section{References}

[1] Abhyankar, H. S., S. C. Graves. "Creating an inventory hedge for Markov-modulated Poisson demand: An 


\section{International Journal of Science and Research (IJSR) \\ ISSN (Online): 2319-7064}

Index Copernicus Value (2013): 6.14 | Impact Factor (2015): 6.391

application and a model". Manufacturing Service Oper. Management 3 306-320, 2001.

[2] Beyer, D., J. Ward. "Network server supply chain at HP: A case study". HP Labs Technical Report HPL-2000-84, Hewlett Packard, Palo Alto, CA, 2000.

[3] Bollapragada, S., T. E. Morton. "A simple heuristic for computing uncertainty policies”. Oper. Res. 47 576-584, 1999.

[4] Chen, F., J.-S. Song. "Optimal policies for multiechelon inventory problems with Markov-modulated demand". Oper. Res. 49 226-234, 2001.

[5] Chen, F. Y., J. K. Ryan, D. Simchi-Levi. "The impact of exponential smoothing forecasts on the bullwhip effect". Naval Res. Logist. 47 269-286, 2000.

[6] Coughlin, R. L. "Optimization and measurement of a worldwide supply chain". S.M. Thesis, Leaders for Manufacturing Program, MIT, Cambridge, MA, 1998.

[7] Ettl, M., G. E. Feigin, G. Y. Lin, D. D. Yao. "A supply network model with base-stock control and service requirements". Oper. Res. 48 216-232, 2000.

[8] Graves, S. C. "A single-item inventory model for a uncertainty demand process". Manufacturing Service Oper. Management 1 50-61, 1999.

[9] Graves, S. C., S. P. Willems. "Optimizing strategic safety stock placement in supply chains". Working paper, http://web.mit.edu/sgraves/www/papers/, 1998.

[10] Graves, S. C., S. P. Willems. "Optimizing strategic safety stock placement in supply chains". Manufacturing Service Oper. Management 2 68-83, 2000.

[11] Graves, S. C., S. P. Willems. "Strategic inventory placement in supply chains: Uncertainty demand". Working http://web.mit.edu/sgraves/www/papers/, 2002.

[12] Humair, S., S. P. Willems. "Optimal inventory placement in networks with clusters of commonality". Oper. Res. 54 725-742, 2006.

[13] Johnson, M. E., E. Anderson. "Postponement strategies for channel derivatives". Internat. J. Logist. Management 11 19-35, 2000.

[14] Kimball, G. E. "General principles of inventory control". J. Manufacturing Oper. Management 1 119-130, 1988.

[15] Kurawarwala, A., H. Matsuo. "Forecasting and inventory management of short life-cycle products". Oper. Res. 44 131-150, 1996.

[16]Lee, H. L., V. Padmanabhan, S. Whang. "Information distortion in a supply chain: The bullwhip effect". Management Sci. 43 546-558, 1997.

[17]Lesnaia, E. "Optimizing safety stock placement in general network supply chains". PhD thesis, MIT Operations Research Center, Cambridge, MA, 2004.

[18] Magnanti, T. L., Z.-J. M. Shen, J. Shu, D. Simchi-Levi, C.-P. Teo. "Inventory placement in acyclic supply chain networks". Oper. Res. Lett. 34 228-238, 2006.

[19] Morton, T. E., D. W. Pentico. "The finite horizon uncertainty stochastic inventory problem: Near-myopic bounds, heuristics, testing”. Management Sci. 41334 343.

[20] Simpson, K. F. 1958. In-process inventories. Oper. Res. $6863-873,1995$ 